\title{
Community-University Partnership Programme (CUPP), University of Brighton
}

\author{
Felix M. Bivens
}

\section{Context}

In 2003, the University of Brighton (UoB) received a grant from the Americanbased Atlantic Philanthropies Foundation to create an institutional infrastructure for supporting CBR in Brighton and the surrounding counties of East and West Sussex. UoB is an amalgam of several professional colleges that have long served the Sussex region. Because of its history in training nurses, teachers, electricians and other occupations, UoB has had a strong tradition of connection with the local community; much of the research carried out by academics has often been of an applied nature. However, because national rankings and government-allotted funding mechanisms in England have not privileged CBR in the past, academics with an interest and history in community research were increasingly encouraged to pursue this kind of work in their own time and to concentrate more on seeking large funding grants connected to national-level research projects. UoB's thenVice Chancellor Sir David Watson felt strongly that universities should play an active role in local communities. Watson's remarks during a television interview drew the attention of Atlantic Philanthropies which approached UoB with an offer of several rounds of centralized funding to allow UoB to support and institutionalize its diffuse CBR efforts. Out of this grant the CUPP programme was born.

\section{Organization/structure}

CUPP describes itself as having three interrelated aims:

- To ensure that the university's resources (intellectual and physical) are available to, informed by and used by its local and sub-regional communities.

- To enhance the community's and university's capacity for engagement for mutual benefit.

- To ensure that CUPP's resources are prioritized towards addressing inequalities within our local communities. (Church and Hart, 2009, p. 9)

CUPP's role was to act as a nexus between academics and community groups, promoting CBR on both sides of the town-gown line. Atlantic Philanthropies' money provided salaries to a new set of university employees whose purpose was to promote and support academics and community groups in developing, 
carrying out and assessing a wide variety of research projects. Many of the CUPP staff came from voluntary sector backgrounds rather than from university roles, which helped them to liaise between the two different cultures, establishing trusted, longstanding relationships with community partners. The money also provided seed grants to support CBR projects. Part of this funding bought out academics' time so they could concentrate on CUPP projects as a fiscally legitimate focus of their work.

\section{Activities}

Although initial projects were based on existing relationships, CUPP took lessons from the science shop model and soon created a helpdesk for fielding community inquiries. As the helpdesk became more established, CUPP devised a more structured mechanism for processing incoming requests. It created a forum called the Senior Researchers' Group (SRG) in which community inquiries were discussed by a group of senior professors from across the whole university. Thus, instead of all requests being assigned to a limited pool of academics, the SRG provided the community access to a much broader range of academics, increasing the odds that community groups would be linked with an appropriate academic. Once the SRG referred the request to a particular researcher, the academic would meet with the organization or community group to flesh out the exact nature and direction of the CBR project. If the match between the academic and the request seemed workable, a research team would be formed, including community members and students. The subsequent work would be supported by members of the CUPP staff, who also oversee administrative elements and conduct evaluations of the engagement process.

CUPP has proven to be a tremendously successful model. Since its inception, CUPP has responded to more than eight hundred community inquiries - three hundred of which were referred on to individual academics by the SGR for one-on-one support - and produced more than seventy major research reports based on communityuniversity research partnerships. (University of Brighton, 2007, p. 5)

It has involved more than 100 academics in CBR projects. Further, it has been successful financially in leveraging several large multimillion pound grants allowing CUPP to work on much larger-scale projects and add additional staff. CUPP has also become a leader in CBR in the UK, winning several nationallevel awards which have boosted not only CUPP's reputation, but that of UoB as a whole. Although Atlantic Philanthropies support expired in 2007, the university made the decision subsequently to underwrite the programme from its own institutional funds. CUPP now operates on an annual budget of $£ 550,000$, which includes support for a staff of seven, in addition to a variety of academic advisors who co-manage the programme and liaise with the various university departments. In 2009, CUPP established a second helpdesk at a UoB satellite campus in Hastings, one of the UK's poorest and most deprived communities. Moreover, community engagement has been prioritized as one of UoB's primary institutional aims in the university's most recent corporate plan. 


\section{Outcomes}

Like the MA in participation (MAP), the curricular impacts of CUPP were not immediate. If not for the committed efforts of its staff, CUPP might not have had any impact on teaching at UoB, since neither the university's management nor Atlantic Philanthropies had planned for incorporating students or teaching modules into the programme. Several years prior to the beginning of CUPP, UoB had received a government grant to create a student volunteer office and the expectation was that this programme and CUPP would operate independently of each other, that there would be opportunities for student service activities in the community but not necessarily for academically credited service learning. The institution's evolution on this subject is found in a comment by one of the Pro-Vice Chancellors who worked closely with CUPP since its formation:

In some ways, initially we'd slightly headed off the service-learning proposition, partly because that wasn't how the thing originally presented itself to us ... In fact, I was one of the people who was least interested in that. I can see the value of it a lot more now and I think we developed it at stage when we were ready for it. The work that Juliet [Millican] has done and the module are now a very strong part of the linkage between the teaching aspects of the institution and the social engagement aspects, and that is a very powerful linkage on both sides - and another way in which [CUPP] has gotten more embedded and bound in. (interview, 2009, pp. 4-5)

The Pro-Vice Chancellor's references an academic module revamped by CUPP staff member Juliet Millican. The year-long course, Community and Personal Development module (CPD), is intended for undergraduate students in their second year. According to the CPD Handbook, course aims include:

- To provide a practical experience to help students to prepare for work placement or subsequent employment and to determine the areas and contacts on which they might focus.

- To practise the skills employers might expect in graduates within an organizational setting.

- To gain a deeper understanding of organizations, of how they work, and of where a student might best fit within them.

- To build up effective communication and interpersonal skills, including giving presentations and working as part of a team.

- To gain experience of dealing professionally with difficult interpersonal situations and to explore a range of options for coping with these.

- To develop an increased awareness of a student's personal skills and the importance of continuous learning and reflection.

- To extend a student's awareness of the broader social and structural issues within the society in which they live. (Millican, 2008, p. 3)

Interestingly, CPD follows a 'sandwich-course' structure paralleling that of MAP. The module runs October to December. Students participate in six weeks of class meetings discussing issues of civil society, participation, active citizenship, 
the history of the UK's voluntary sector and organizational dynamics. The classes are designed to be highly interactive and allow for students to contribute significantly to class discussions. During this term, students also set up an internship and research project with a non-profit organization in Brighton.

More than simply a placement, the aim is for students to carry out a specific project for a group or to complete a piece of consultancy research for the host organization. Course facilitators arrange 'matching events' which bring representatives from local volunteer and community organizations to the UoB campus to meet CPD students and expedite the process of linking students with a host organization. At the end of term, students submit a learning plan explaining the organization they will be working with and the nature of their research. January to March - there are only two class meetings - students put their energy to field projects. As in MAP, a reflective approach is encouraged. Students are required to keep a journal in which they detail their work experience and reflect on their changing perceptions of the organization and themselves. They are asked to assess the management style of the organization and the resulting work environment for staff and for users of the various programmes and services. CPD students are expected to log fifty hours of work with their host organization.

The April to June term parallels the first term, with six class meetings where students come together to discuss their field experiences with course facilitators. Students are exposed to more concepts for understanding organizations and more literature and theory on civil society and citizen participation. They do reflective writing about their experiences to share with tutors and classmates. This prepares students for their final assessments, a written analysis of the host organization and a written assessment of their experience, noting specifically the professional and interpersonal skills they developed. The course concludes with students presenting to their peers.

CPD has been a significant force in helping to bridge the gap between student volunteerism and CBR. Undergraduate students volunteer, with a clear project in mind through discussions with their host organization. Moreover, CPD has also provided a mechanism for students to receive academic credit for their work in the community. The scale of the CPD module is also significant. Several different schools within the university have bought into the CPD model and have made it a requirement for their undergraduates. As such, the annual intake for the module is more than 250 students, broken into seven or eight different sections of approximately thirty students, each with a different tutor working with the group across the academic year. This represents a significant growth in the CPD programme; when CUPP inherited the module, it had an annual enrolment of approximately five students! The current need for so many course tutors has actually precipitated an important pedagogical impact as well in that many of the CPD tutors are also CUPP staff members. This is significant because CUPP staff come from community and voluntary sector backgrounds. As such, CPD has created an important opening for allowing different kinds of individuals into the classroom. Indeed, many in the CUPP staff bring ten to fifteen years of voluntary sector work with them, particularly relevant and helpful to students. 
Although CPD has been very successful, it has struggled to keep pace with the volume of students taking the course, and with their disciplinary diversity. Students in one section of CPD may come from fields as diverse as education, criminology and psychology. This can sometime make finding common ground for discussion for undergraduate students difficult, particularly when discussing the specific operations and logics of their respective host organizations. For this reason, CPD is likely to be reorganized so that multiple, specialized CPD modules can be created and embedded within each discipline: students from the same field can take the course together and have more synergy in discussions and in locating relevant host organizations and research projects.

Although CPD is the most sizable contribution to UoB's curriculum generated by CUPP's work, it is not the only one. CUPP has also been responsible for designing two other modules, including Understanding Participation in the School of Education, and Partnerships and Participation with Marginalized Groups in the School of Nursing and Midwifery. More recently, CUPP's Millican helped to introduce a new undergraduate politics module which feeds into the CPD programme. Another important outgrowth of CUPP's CBR is the Inclusive Arts MA programme, in 2008. One of CUPP's earliest pilot projects enabled UoB students from the School of Art and Architecture to work with adult artists who were developmentally challenged. The project was spearheaded by local artist and activist Alice Fox who had originally organized these artists into a group called Rocket Artists. The initial collaboration was very successful and resulted in a show for artists and UoB students at the Tate Modern gallery in London. They remained eager to continue working together. Based on her work with CUPP, Fox was hired by the School of Art and Architecture faculty to teach several classes that allowed these artistic collaborations to develop further. In time, Fox expanded her vision and aspired to create a full MA programme in Inclusive Arts which would help train students to create their own arts programmes for people with severe learning difficulties and other developmental challenges. As with CPD, Inclusive Arts has enabled individuals with non-traditional backgrounds to come into the teaching faculty.

CUPP has also enabled hundreds of students at undergraduate, graduate and postgraduate levels to take part in CBR projects. Many of these opportunities have come about in the process of carrying out inquires submitted to the helpdesk. In other cases, faculty members have been able to solicit funding to carry out community research with an entire class of students. CUPP is also becoming an important resource for doctoral students - from UoB as well as other universities in the UK - researching various aspects of CBR. 